\title{
Intra-individual behavioral variability displayed by tuna at fish aggregating devices (FADs)
}

\author{
Marianne Robert ${ }^{1,2,7, *}$, Laurent Dagorn ${ }^{1}$, John David Filmalter ${ }^{1,3,4}$, \\ Jean-Louis Deneubourg ${ }^{2}$, David Itano ${ }^{5}$, Kim Holland ${ }^{6}$
}

${ }^{1}$ UMR EME, Institut de Recherche pour le Développement (IRD), avenue Jean Monnet BP 171, 34203 Sète cedex, Seychelles

${ }^{2}$ Unit of Social Ecology, Université Libre de Bruxelles (ULB), CP 231 Bd du Triomphe, 1050 Brussels, Belgium

${ }^{3}$ The South African Institute for Aquatic Biodiversity (SAIAB), Somerset Street, Grahamstown 6139, South Africa ${ }^{4}$ Rhodes University, PO Box 94, Grahamstown 6140, South Africa

${ }^{5}$ Pelagic Fisheries Research Program, University of Hawaii at Manoa, 1000 Pope Road, MSB 312 Honolulu, Hawaii 96822, USA ${ }^{6}$ Hawaii Institute of Marine Biology, PO Box 1346, Kane'ohe, Hawaii 96744, USA

${ }^{7}$ Present address: IFREMER, 8 rue Toullec, 56100 Lorient, France

\begin{abstract}
Fishers have exploited the associative behavior displayed by several pelagic fish species with floating objects for decades, through the use of man-made fish aggregating devices (FADs), which facilitate the capture of such species. However, our understanding of this associative behavior and its adaptive value is poor and the scientific community is ill-equipped to provide fishery managers with science-based recommendations on the impacts of FADs on ecosystems. In an array of 13 anchored FADs around Oahu, Hawaii, USA, 72 yellowfin tuna Thunnus albacares were equipped with internal acoustic tags, which facilitated the continuous monitored of their presence and absence around each FAD using automated acoustic receivers. Data were analyzed using survival curves with the objective of determining the behavioral dynamics of fish joining and leaving the FADs. Residence times at FADs were characterized by 4 behavioral modes: briefly passing near a FAD (average $13.1 \mathrm{~min}$ ), short association (average $2.9 \mathrm{~d}$ ), and 2 long association behaviors (13.8 and $23.2 \mathrm{~d}$, respectively). Statistical analyses suggest that different behavioral modes were likely dependent upon local conditions around the FAD at a given time (environmental factors or social interactions). We observed 2 behavioral modes for absence times from FADs: short (2.8 d) and long (infinite). More importantly, individuals exhibited behavioral variability, switching between short and long residence times at FADs. This suggests that large pelagic fish can display a range of behavioral responses while in an array of FADs, challenging the common hypothesis of a single behavioral pattern, which could ultimately lead to an ecological trap. Survival curves were best fitted with exponential models, suggesting that underlying behavioral processes were time independent.
\end{abstract}

KEY WORDS: Behavioral variability $\cdot$ Fish aggregating device $\cdot$ FAD $\cdot$ Yellowfin tuna $\cdot$ Acoustic tagging $\cdot$ Residence time $\cdot$ Survival curve

Resale or republication not permitted without written consent of the publisher

\section{INTRODUCTION}

Many tropical pelagic fish species such as yellowfin tuna Thunnus albacares, bigeye tuna $T$. obesus, skipjack tuna Katsuwonus pelamis, dolphinfish Coryphaena hippurus, wahoo Acanthocybium solandri, silky shark Carcharhinus falciformis and oceanic white tip C. longimanus sharks are known to associate with floating objects (Castro et al. 2002). Different hypotheses have been advanced to explain why different species associate with floating objects, but for most species the reasons remain unclear. Among 
these hypotheses, the most commonly accepted are the indicator log hypothesis (Hall 1992), where natural floating objects could be used by fish as indicators of productive areas, and the meeting point hypothesis (Dagorn \& Freon 1999, Freon \& Dagorn 2000), where fish make use of floating objects to increase the encounter rate between individuals to form larger schools.

Initially, this associative behavior must have evolved around natural floating objects (i.e. logs). In the past 3 decades, fishermen have taken advantage of this behavior by building and deploying manmade floating structures called fish aggregating devices (FADs) for attracting and concentrating pelagic fish (Fonteneau et al. 2000). A large portion of the world's catches of tropical tunas come from fish associated with floating objects. FADs can be moored in coastal areas and utilized by artisanal fisheries or deployed in the open ocean and exploited by distant water purse seine fisheries. These large-scale fisheries deploy thousands of drifting FADs which in all likelihood modify the pelagic habitat. Concerns have arisen regarding the impacts of such habitat modification on pelagic fish at both individual and population level (Marsac et al. 2000, Menard et al. 2000, Hallier \& Gaertner 2008).

In order to better understand this associative behavior, its adaptive value and assess the effects of FADs on the ecology of fish stocks, it is important to first determine the amount of time that fish remain associated with a floating object. Residence time is defined as the amount of time spent in a particular location and provides a relevant and robust signal for investigating space usage patterns (Barraquand \& Benhamou 2008). The recent progress in electronic tag technology has allowed marine biologists to collect large amounts of data on the movements and behavior of fish. Active acoustic telemetry, for instance, has been successfully applied to the study of tropical tunas near anchored FADs, providing information on movements, residency patterns and orientation capabilities of FAD-associated tunas (Cayré \& Chabanne 1986, Holland et al. 1990, Brill et al. 1999, Dagorn et al. 2000, Girard et al. 2004). Passive acoustic telemetry experiments have been conducted to collect information on tuna behavior (e.g. movements, residency) in arrays of anchored FADs over long time scales (Klimley \& Holloway 1999, Ohta \& Kakuma 2005, Dagorn et al. 2007). Despite the growing literature on tuna-FAD relationships, many questions still remain regarding the associative behavior of tunas. In particular, it is not known if tuna display different behavioral patterns (e.g. residence times) at
FADs. Some studies (e.g. Hallier \& Gaertner 2008) consider that a tuna has the same probability of associating with a FAD, irrespective of the quality of the surrounding oceanic environment. In other words, the duration of an association event would primarily be dictated by the presence of a FAD and not by the environmental conditions around the FAD. If this is the case, FADs could likely act as ecological traps (Marsac et al. 2000, Hallier \& Gaertner 2008). However, if tuna adapt the duration of their association with a FAD according to local environmental conditions, the interplay between FADs and local conditions would determine whether tunas could be trapped in arrays of FADs. As such, developing an understanding of the residence times of tuna at FADs (as well as their absence from FADs) is key important information in the investigation of the ecological trap hypothesis.

Using the statistical properties of the distribution of times that yellowfin tuna spent at, and away from, FADs in an anchored array, we aim to identify whether a single behavioral mode is followed, or if multiple patterns appear which may depend on the individual, the area (FAD) or the time period. Moreover, our study goes beyond the study of tuna at FADs and proposes an innovative approach based on the distribution of residence times (as opposed to the mean) to investigate behavioral variability in acoustically tagged animals.

\section{MATERIALS AND METHODS}

\section{Experimental design}

The island of Oahu within the main Hawaiian Island chain (USA) is surrounded by an array of 13 anchored FADs, identified by either 1 or 2 letters (Fig. 1). All FADs were identical in structure and consist of a yellow surface buoy anchored using concrete blocks. An automated acoustic receiver (Vemco VR2, Amirix Systems) was attached to the mooring line of each of these FADs, $\sim 20 \mathrm{~m}$ from the surface. Tagging was conducted at $5 \mathrm{FADs}$ in the array $(\mathrm{CO}, \mathrm{HH}, \mathrm{LL}$, $\mathrm{R}$ and $\mathrm{S}$, Fig. 1). Tagging episodes are described in Table 1. From September 2002 to January 2005, 72 yellowfin tuna (54 to $95 \mathrm{~cm}$ fork length, FL) were captured and tagged. The tagging procedure is the same as that described in Dagorn et al. (2007). Coded Vemco V16 tags $(69 \mathrm{kHz}, \mathrm{V} 16-4 \mathrm{H}-\mathrm{R} 256$, diameter $16 \mathrm{~mm}$, length $68 \mathrm{~mm}$, weight in air $24 \mathrm{~g}$ ) were used for fish tagged from 2002 to 2004, and coded Vemco V9P tags $(69 \mathrm{kHz}$, V9P-2H-S256, diameter $9 \mathrm{~mm}$, 


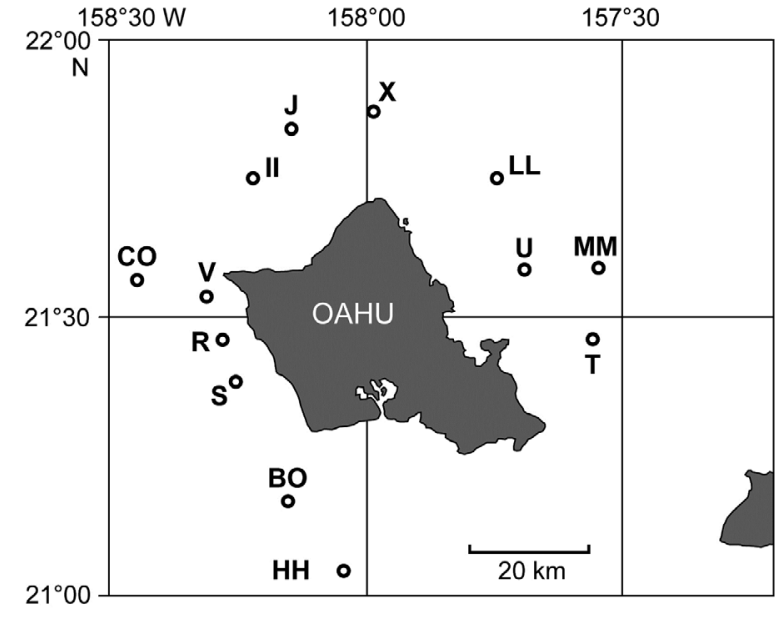

Fig. 1. Fish aggregating devices (FADs) around the island of Oahu (Hawaii). Each of the 13 FADs is coded by 1 or 2 letters

Table 1. Sampling strategy: Number of yellowfin tuna tagged, size range and date of tagging. Fish aggregating devices (FADs); shown in Fig. 1

\begin{tabular}{|lcccc|}
\hline FAD & Year & Month & $\begin{array}{c}\text { Number } \\
\text { of fish }\end{array}$ & $\begin{array}{c}\text { Size range } \\
\text { (cm) }\end{array}$ \\
\hline S & 2002 & Sep-Oct & 16 & $54-68$ \\
CO & 2003 & Feb & 19 & $59-86$ \\
HH & 2003 & Mar, Apr, May & $5,3,1$ & $62-81$ \\
LL & 2004 & Jan, Feb, Mar & $6,4,3$ & $63-95$ \\
R & 2005 & Jan & 6 & $67-76$ \\
S & 2005 & Jan & 9 & $68-83$ \\
\hline
\end{tabular}

length $47 \mathrm{~mm}$, weight in air $6.4 \mathrm{~g}$ ) for fish tagged in 2005. The ratio of the weight of the tag (in air) to the estimated weight of the fish was always $<0.5 \%$. An external Hallprint $11 \mathrm{~cm}$ plastic dart tag was inserted through the pterygiophores of the second dorsal fin to maximize reporting of recaptures.

\section{Ethical note}

Fish handling procedures were in accordance with established best practices and were specifically approved by the University of Hawaii (Institutional Care and Use Committee-IACUC). The total time that a tuna was out of the water was $<2$ min. No adverse effect was directly observed in this study or has ever been reported across all other studies carried out using this technique on similar sized tunas around the world
(Klimley \& Holloway 1999, Schaefer \& Fuller 2002, Ohta \& Kakuma 2005, Dagorn et al. 2007, Schaefer et al. 2007).

\section{Residence and absence times}

In order to characterize the behavior of tuna in an array of FADs, we focus on 2 main variables: (1) the time tuna spend associated with a FAD (hereafter referred to as continuous residence time, CRT) and (2) the interval of time between 2 consecutive associations with a FAD (hereafter referred to as continuous absence time, CAT). Ohta \& Kakuma (2005) defined the CRT as the duration for which a tagged tuna was monitored around a FAD without an absence $>24 \mathrm{~h}$, a definition also utilized by Dagorn et al. (2007). We defined a CAT as the time between 2 consecutive CRTs greater than $24 \mathrm{~h}$ when the tuna returned to the same FAD but with no minimum time if the fish moved from one FAD to another. We calculated the CRTs and CATs displayed by each tagged tuna during their stay in the array of FADs. In order to investigate the effects of location (a specific FAD) and time on the distributions of CRTs and CATs, we developed a coherent spatio-temporal statistical unit (SU) that is defined as the series of CRTs from several tuna that occurred at a single FAD (or, in the case of CATs, the periods between associations with FADs) during consecutive months of a given year. A CRT is assigned to the arrival month and year at a FAD. A CAT is assigned to the month and year at which the tuna leaves a FAD. A SU had to consist of a minimum of 10 events (CRTs or CATs) to be considered in this analysis. Following these criteria, 7 and 2 SUs of CRTs and CATs, respectively, were obtained from the dataset (Table 2).

Table 2. Definition of the 7 and the 2 statistical units (SUs) of continuous residence times (CRTs) and continuous absence times (CATs), respectively, for each fish aggregating device (FAD), year and month (FAD-Year-Months). -: no data

\begin{tabular}{|c|c|c|c|c|c|c|c|c|c|c|c|}
\hline \multirow{2}{*}{ FAD } & \multirow{2}{*}{ Year } & \multirow[b]{2}{*}{ Jan } & \multirow[b]{2}{*}{ Feb } & \multirow[b]{2}{*}{ Mar } & \multicolumn{2}{|c|}{ Month } & \multirow[b]{2}{*}{ Jun } & \multirow[b]{2}{*}{ Jul } & \multirow[b]{2}{*}{ Oct } & \multirow[b]{2}{*}{ Nov } & \multirow{2}{*}{ SUs } \\
\hline & & & & & Apr & May & & & & & \\
\hline \multicolumn{12}{|l|}{ CRT } \\
\hline $\mathrm{R}$ & 2002 & - & - & - & - & - & _- & - & 11 & 2 & R-2002-ON \\
\hline V & 2003 & - & - & 8 & 3 & 3 & - & - & - & - & V-2003-MM \\
\hline $\mathrm{HH}$ & 2003 & - & - & 6 & 4 & 5 & 4 & - & - & - & HH-2003-MJ \\
\hline $\mathrm{CO}$ & 2003 & - & 10 & 13 & - & - & - & - & - & - & CO-2003-FM \\
\hline LL & 2004 & - & 6 & 9 & - & - & - & - & - & - & LL-2004-FM \\
\hline $\mathrm{R}$ & 2005 & 11 & 7 & 2 & 3 & - & - & - & - & - & R-2005-JA \\
\hline $\mathrm{S}$ & 2005 & 12 & 13 & 11 & 1 & - & - & - & - & - & S-2005-JA \\
\hline \multicolumn{12}{|c|}{ CAT } \\
\hline & 2003 & - & - & 20 & 11 & 16 & 9 & 7 & - & - & 2003-MJ \\
\hline & 2005 & 13 & 18 & 13 & 4 & - & - & - & - & - & 2005-JA \\
\hline
\end{tabular}




\section{Comparison of SUs}

We evaluated the probability of a tuna leaving a FAD (end of a CRT) or of re-associating with a FAD (end of a CAT). The survival function $S(t)=\operatorname{Pr}(T>t)$ is the probability that the duration of a CRT (probability of leaving a FAD) or a CAT (probability of joining a FAD) is greater than some specified value $t$, with $T$ being a random variable denoting the duration of a CRT or a CAT. We used the Cox proportionalhazards regression model (Cox 1972) to compare the survival curves of the different SUs with the objective of identifying any homogeneous family of SUs. Homogeneous families were defined as groups of SUs that showed no statistical difference.

\section{Modeling the survival curves}

A survival curve was developed for each homogeneous family of SUs. We fitted and compared 3 models to each of these survival curves to identify which biological process (model) best explained the data using the Akaike information criterion (AIC, Akaike 1973) and a quantile-quantile plot. The first 2 models were single or multiple exponential distribution models where the probability of a tuna leaving or joining a FAD is time independent and the mean residence time being the inverse of the estimated probability density per unit of time. The third was a general power law model where the probability of a tuna leaving or joining a FAD would depend on the amount of time the tuna has spent at the FAD or between associations. Within a family of SU more than one behavioral mode could exist.

\section{Behavioral variability}

Initially, we tested whether a correlation existed between the length of CRTs and the length of the preceding or following CATs to investigate whether these 2 variables influenced each other. Then, we investigated whether the same individual could exhibit CRTs representing different behavioral modes. Finally, we selected individuals that exhibited a minimum of 5 CRTs to estimate the probability of displaying a particular behavioral mode and examine whether this probability was the same amongst individuals using a chi-squared test.

Statistical analyses were performed in R 2.9.0 (www. r-project.org/), using the survival library. We considered tests to be statistically significant at an $\alpha$ of 0.05 .
The Supplement (www.int-res.com/articles/suppl/ m484p239_supp.pdf) material includes detailed information on the equations fitted, statistical procedures used to investigate behavioral variability, and detailed results of model fitting and comparison.

\section{RESULTS}

\section{Continuous residence times (CRTs)}

The Cox model showed that the population of the 7 SUs of CRTs was not homogeneous (Wald test: $\mathrm{n}=144, \mathrm{p}=1.13 \times 10^{-10}$, Table 3a \& Fig. 2). Three different families were distinguished: (1) FADs HH-2003March-June and LL-2004-February-March (Table 3a), (2) FAD R-2002-October-November (Table 3a,b) and (3) FADs V-2003-March-May, CO-2003-FebruaryMarch, R-2005-January-April and S-2005-JanuaryApril (Table 3c). The survival curves for these families were tested for best fit. For family (1), the AIC slightly favored the double exponential model (Table 4). However, one behavioral mode produced by this model had a probability not statistically different from zero (and characterizing only $5 \%$ of the CRTs), while the probability of the second mode was similar to that produced by the single exponential model (Table S1 \& Fig. S1 in Supplement 1). We therefore selected the single exponential model showing a single behavioral mode with a mean CRT of $23.2 \mathrm{~d}$. For family (2), the AIC indicated that the single exponential model had the best goodness of fit (Table 4), showing a mean CRT of 13.8 d (Table S2 \& Fig. S2 in the Supplement). For family (3), the AIC suggested that the double exponential model provided the best fit to the data (Table 4). The first behavioral mode represented $64 \%$ of the CRTs with a mean duration of $2.9 \mathrm{~d}$, while the second behavioral mode represented $36 \%$ of the CRTs with a mean duration of 0.009 d (13.1 min) (Table S3 \& Fig. S3 in the Supplement). The 2 short behavioral modes (13.1 min and $2.9 \mathrm{~d}$ ) were commonly found to occur simultaneously at the same FAD, whereas when the longer behavioral modes (13.8 or $23.2 \mathrm{~d}$ ) were observed, they occurred in isolation.

Different behavioral modes were observed at different FADs during the same time period (FAD V and $\mathrm{HH}$ from March to June 2003, Table 3a), suggesting that the time period was not the only driving factor. Furthermore, the characteristics of a specific FAD can also be excluded as different behavioral modes were observed at the same FAD during 2 distinct time periods (FAD R in 2002 and 2005, Table 3b). 
Table 3. Cox regression models used to compare the statistical units (SUs). Results of the global test (Wald test) and the estimated parameters of the models are given. SUs are summarized by the FAD-Year-Months (the first and the last month of the SUs are given). (a) Comparison of the 7 statistical units for continuous residence time (CRT). $(\mathrm{a}, \mathrm{b}, \mathrm{c})$ Step by step removal of SUs so as to identify homogeneous families of SUs. (d) Comparison of the 2 SUs for continuous absence time (CAT)

\begin{tabular}{|c|c|c|c|c|c|c|}
\hline \multirow{2}{*}{$\begin{array}{l}\text { Wald } \\
\text { test }\end{array}$} & \multirow{2}{*}{$\mathrm{p}$-value } & \multirow[t]{2}{*}{$\mathrm{n}$} & \multicolumn{4}{|c|}{ Estimated parameters of the Cox model —_ } \\
\hline & & & Reference & SU & $\exp ($ coef) & p-value \\
\hline \multicolumn{7}{|l|}{ CRT } \\
\hline \multirow[t]{6}{*}{$\mathrm{a}$} & $1.13 \times 10^{-10}$ & 144 & HH-2003-MJ & LL-2004-FM & 0.77 & 0.53 \\
\hline & & & & $\mathrm{R}-2002-\mathrm{ON}$ & 3.09 & 0.01 \\
\hline & & & & R-2005-JA & 15.08 & $1.78 \times 10^{-9}$ \\
\hline & & & & S-2005-JA & 12.20 & $2.80 \times 10^{-9}$ \\
\hline & & & & V-2003-MM & 16.54 & $6.51 \times 10^{-9}$ \\
\hline & & & & CO-2003-FM & 6.75 & $1.46 \times 10^{-5}$ \\
\hline \multirow[t]{4}{*}{$\mathrm{b}$} & $19.17 \times 10^{-4}$ & 110 & R-2002-ON & R-2005-JA & 6.30 & $4.00 \times 10^{-5}$ \\
\hline & & & & S-2005-JA & 5.02 & $9.88 \times 10^{-5}$ \\
\hline & & & & V-2003-MM & 6.89 & $6.02 \times 10^{-5}$ \\
\hline & & & & CO-2003-FM & 2.75 & 0.02 \\
\hline \multirow[t]{3}{*}{$\mathrm{C}$} & $5.23 \times 10^{-2}$ & 97 & R-2005-JA & S-2005-JA & 0.78 & 0.37 \\
\hline & & & & V-2003-MM & 1.10 & 0.79 \\
\hline & & & & CO-2003-FM & 0.44 & 0.01 \\
\hline \multicolumn{7}{|l|}{ CAT } \\
\hline d & 0.12 & 109 & 2003-MJ & 2005-JA & 0.73 & 0.12 \\
\hline
\end{tabular}
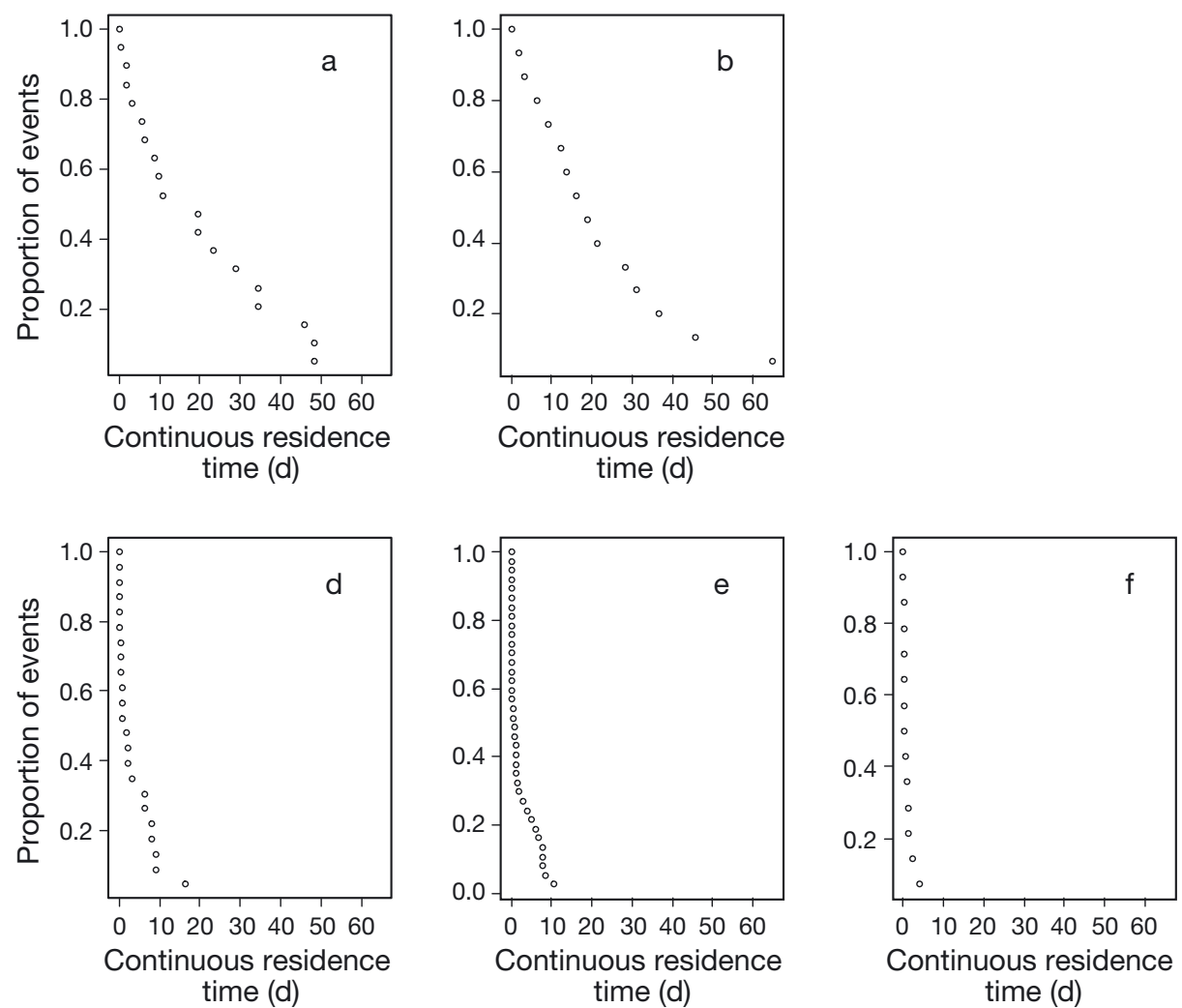

\section{Continuous absence time (CATs)}

The Cox model indicated that the 2 SUs were similar, forming 1 homogeneous family (Wald test: $\mathrm{n}=109, \mathrm{p}=$ 0.122 , Table $3 \mathrm{~d}$ ). The survival curve including the 2 SUs was tested for best fit. The AIC suggested that the double exponential model provided the best fit (Table 4), whereas the data were poorly represented by both the single exponential and power law models. The first behavioral mode represented $93 \%$ of the CATs with a mean duration of $2.8 \mathrm{~d}$, while the second behavioral mode represented $7 \%$ of the CATs with an extremely small probability of returning to a FAD (the probability was not statistically different from zero, Table S4 \& Fig. S4 in Supplement 1). In addition, no relationship was observed between the length of CRTs and preceding or following CATs (Fig. 3).
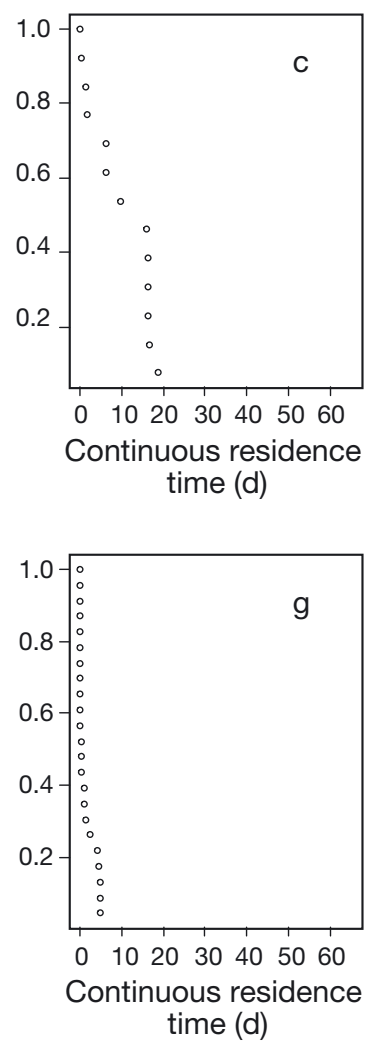

Fig. 2. Distribution of survival curves for the 7 statistical units defined for the continuous residence time (CRT). Three different families were distinguished: (a,b) CRTs under FADs HH-2003-March-June and LL-2004-February-March respectively, (c) CRTs under FAD R-2002-October-November, and (d,e,f,g) CRTs under FADs CO-2003-February-March, S-2005-JanuaryApril, V-2003-March-May, and R-2005-January-April, respectively 
Table 4. Comparison of the goodness of fit between models. Values of Akaike information criterion (AIC) are given for the 3 models tested on each homogeneous family of statistical units (SUs) for both the continuous residence time (CRT) and the continuous absence time (CAT). For CRT, Family 1 corresponds to CRTs displayed under FADs HH-2003March-June and LL-2004-February-March; Family 2 to CRTs displayed under FAD R-2002-October-November and Family 3 to CRTs displayed under FADs CO-2003-FebruaryMarch, S-2005-January-April, V-2003-March-May, and R-2005-January-April

\begin{tabular}{|cccc|}
\hline & Family of SUs & Model & AIC \\
\hline CRT & 1 & Single exponential & -152.19 \\
& & Multiple exponential & -155.12 \\
& & Power low & -137.48 \\
& \multirow{2}{*}{2} & Single exponential & -20.01 \\
& & Multiple exponential & -18.34 \\
& \multirow{2}{*}{3} & Power low & -19.10 \\
& & Single exponential & -179.54 \\
& & Multiple exponential & -343.70 \\
CAT & Power low & -211.12 \\
& & Single exponential & -415.50 \\
& & Multiple exponential & -416.55 \\
& & Power low & -394.93 \\
\hline
\end{tabular}

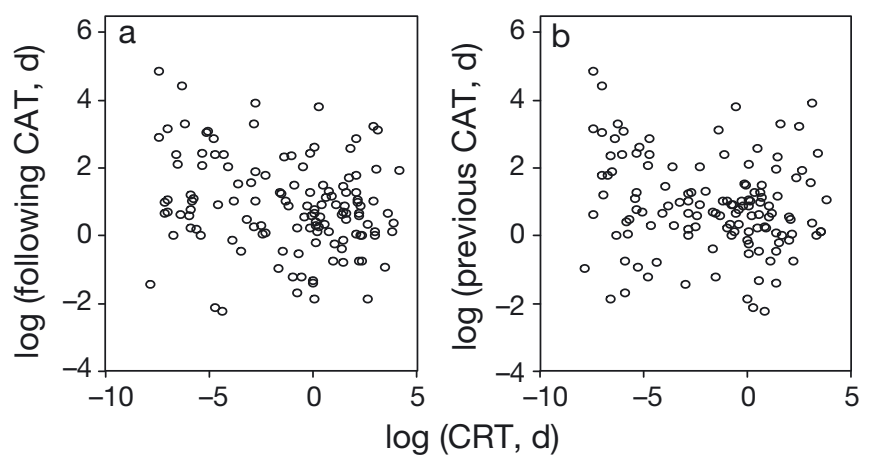

Fig. 3. Length of continuous residence time (CRT) against length of the preceding or following continuous absence time (CAT) (on a logarithmic scale)

\section{Behavioral variability}

To identify intra individual variability in behavior, it was necessary to combine the 4 observed behavioral modes of residency at FADs into 2 groups considered to be short (the 0.009 and $2.9 \mathrm{~d}$ behavioral modes) and long (the 13.8 and $23.2 \mathrm{~d}$ behavioral modes) CRTs, separated by the threshold of $5.5 \mathrm{~d}$ (the mean of all CRTs). As such, $48 \%$ of the tagged individuals exhibited both short and long CRTs. Moreover, the probability of performing a short CRT was similar for all individuals that displayed at least 5 CRTs (chisquare test: $\mathrm{n}=9, \mathrm{p}=0.17$ ).
Fig. 4 illustrates the behavior of 2 tagged tuna while in the array of FADs. Yellowfin tuna 139H0 (69 $\mathrm{cm}$ FL) was tagged at FAD LL where it remained for $64 \mathrm{~d}$. Then, it associated with other FADs, staying $0.7 \mathrm{~d}$ at FAD $\mathrm{X}, 14 \mathrm{~d}$ at FAD J and $3 \mathrm{~d}$ at FAD V (Fig. 4a). Tuna 139H0 exhibited the 4 behavioral modes during the time it spent associated with the array of FADs of Oahu. Yellowfin tuna 114H0 $(74 \mathrm{~cm}$ FL) displayed 4 CATs: one very long of ca. $55.5 \mathrm{~d}$, after which it re-associated with the array and displayed short CATs of ca. 1.5, 3.2, and $3.6 \mathrm{~d}$ (Fig. 4b).

\section{DISCUSSION}

Acoustic telemetry provides data on movements and residence times and has been applied to a wide variety of species (Voegeli \& Pincock 1996, Heupel et al. 2006) including tuna (Ohta \& Kakuma 2005, Dagorn et al. 2007). Through the mathematical framework of survival analysis we have extracted new information from this kind of data. In particular, our analysis facilitated the exposure of the underlying behavioral patterns responsible for the dynamics of FAD aggregations.

When the distribution of times tuna spent between 2 associations (CATs) was considered, 2 behavioral modes were observed, short (2.8 d) and long (infinite) irrespective of the period. The short mode likely represents the behavior of tuna that stayed within the array. The long mode is the result of very few observations where tuna returned to the array after extended periods of absence (roughly $2 \mathrm{mo}$ ). Even though these individuals returned, the probability of doing so was not different from zero (i.e. was equivalent to a final departure). All fish eventually left the array (data not included in the analysis), which also corresponds to infinite (very long) CATs. These 2 categories of CATs both correspond to the same behavioral mode: if a tuna returns after an extended period of absence or if it never returns at all, it is still displaying the same behavior.

Four behavioral modes are responsible for the continuous residence times displayed by tunas around FADs in Hawaii. One behavioral mode (mean of $13.1 \mathrm{~min}$ ) corresponds to tuna briefly passing near a FAD without associating with it. The other modes correspond to real associations that were either short (mean of $2.9 \mathrm{~d}$ ) or long (mean of 13.8 and $23.2 \mathrm{~d}$, respectively). These behavioral modes of residency depended on the conditions surrounding a FAD during a particular time period, rather than a reflection of the intrinsic characteristics of a FAD, the time of 

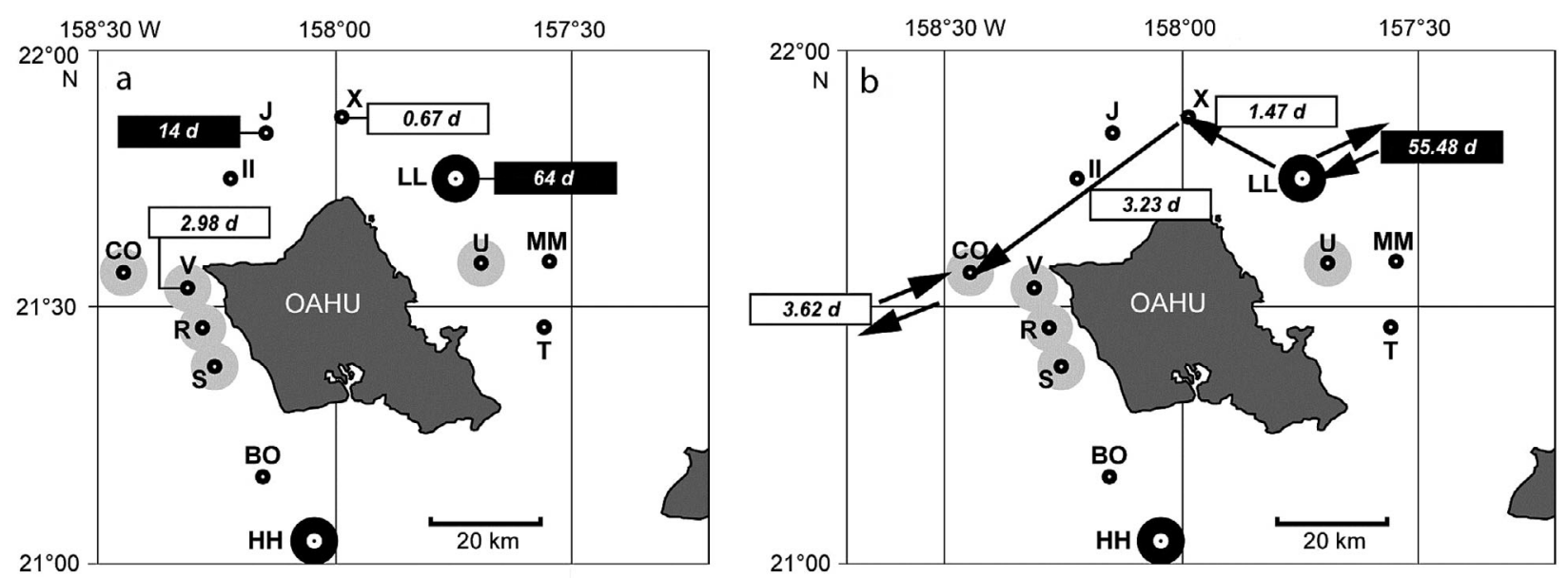

Fig. 4. Intra-individual variability displayed by tuna in an array of fish aggregating devices (FADs). (a) A tagged tuna (ID tag 139H0, $69 \mathrm{~cm} \mathrm{FL,} \mathrm{tagged} \mathrm{at} \mathrm{LL)} \mathrm{that} \mathrm{displayed} \mathrm{long,} \mathrm{short} \mathrm{and} \mathrm{very} \mathrm{short} \mathrm{continuous} \mathrm{residence} \mathrm{times} \mathrm{at} \mathrm{FADs} \mathrm{(CRTs).} \mathrm{(b)} \mathrm{A}$ tagged tuna (ID tag114H0, $74 \mathrm{~cm}$ FL) that displayed both long and short continuous absence times (CATs). Small circles: the location of the FADs. Large circles: FADs characterized by long (black) and short (grey) residence times (in days). Rectangles: duration of long (black) and short (white) CRTs or CATs displayed by the tagged tuna. CRTs are assigned to their corresponding FAD using a thin black line. Black arrows illustrate the movement between FADs displayed by the tagged tuna during a CAT

year at which they occurred or the individual expressing them. The exponential distribution of survival curves also supports the idea that the conditions surrounding a FAD determine the duration of residency as several tuna displayed the same behavioral mode when associated with the same FAD during the same period.

Our observation of several behavioral modes could be explained either through the existence of several behavioral phenotypes within the population (each fish exhibiting only 1 behavioral mode) or alternatively, several modes within the behavioral repertoire of each individual. The sizes of the tuna monitored meant that they were not sexually mature-negating the need to consider spawning or mating behavior. Other key individual parameters may explain the spatio-temporal variability in the observed responses at FADs; however, these do not explain the intra individual variability in residency patterns highlighted by our results. Our results show that yellowfin tuna have the ability to change their behavior while in the array and do not support the existence of distinct behavioral phenotypes. The fundamental information we have shown is key for addressing the ecological trap hypothesis (Marsac et al. 2000, Hallier \& Gaertner 2008). Hallier \& Gaertner (2008) implied that a tuna has the same probability of associating with a FAD irrespective of the quality of the surrounding oceanic environment. As such, if FADs were located in a poor habitat they could have deleterious effects on fish that remain associated with them, leading to an ecological traps. However, our results show that a tuna's response to a FAD is not constant and depends on local conditions, challenging this common hypothesis of a single behavioral pattern exhibited by tuna during FAD associations.

Based on the data available, it was not possible to determine the factors that trigger one mode or the other. The best fitting models were always exponential in nature, which suggests that all behavioral processes share a common trait of independence from time. Identification of the underlying mechanisms and driving factors is far from trivial, especially when dealing with animals that occupy vast and difficultto-access environments. The conditions responsible for the time that tuna stay around a FAD could include local oceanic conditions, e.g. temperature and oxygen (Cayré \& Marsac 1993, Brill et al. 1999, Schaefer \& Fuller 2010), prey availability (Musyl et al. 2003, Ohta \& Kakuma 2005, Graham et al. 2007), and the physiological states of tuna or the number of conspecifics in the association (Soria et al. 2009, Capello et al. 2011). In the literature, satellite remote sensing data (SRS) are often used to investigate relationships between tuna abundance (typically represented by CPUE) and mesoscale structures such as upwellings, eddies, or peaks of chl a. The scale of such structures far exceeds that of our study. Even if remote sensing data could be used to assess sea surface temperature differences at an appropriate scale, it is widely recognized that a key component of tuna habitat is the depth of the surface mixed layer and the thermal and oxygen structure of the deeper water below it. None of these phenomena are amenable 
to remote sensing. However, it can be reasonably assumed that oceanic conditions at a given period in time are the same at all sites in the study array. Moreover, Ohta \& Kakuma (2005) could not find any effect of oceanographic conditions at FADs on the residence times of tuna, and suggested that biotic factors are likely to drive these associations. Monitoring the biotic factors, as well as the number of congeners aggregated around FADs, could be done from time to time, through appropriate acoustic surveys. However, current technology does not allow for the continuous monitoring of this environment, compatible with the time scales over which acoustically tagged tuna are monitored around FADs. An important finding from our study was the absence of relationships between CRTs and the preceding or following CATs, suggesting that factors driving the duration of a stay at a FAD and the duration of the absence period are independent.

The identification of the factors that determine the movements of tuna have been the subject of decades of research by scores of scientists. Our study is one part of that overall effort. One valuable output of our work indicates that future field research should focus on the collection of simultaneous data. This should include data on the residence times of tuna at a FAD, the abundance of tuna at this FAD and the internal physiological states of individuals, along with data on the biotic environment surrounding the FAD (prey densities, presence of predators). This would require the development of new technologies, but is key to understanding this associative behavior more completely and for assessing the impacts of FADs on the ecology of tuna. Understanding the behavior of tuna whilst they are away from FADs is of equal importance. Double tagging (i.e. acoustic with archival tags) would provide insights into the factors driving the length of time between 2 associations and the motivations that lead tuna to associate with floating structures.

Our results on the exponential nature of the survival curves, the estimated proportion of the different behavioral modes and probabilities of a tuna joining or leaving a FAD provide information that can be used to model the dynamics of fish abundance at FADs. The methodology developed in our study can not only be used to develop a better understanding of the behavior of other fish species that associate with floating structures ( $>300$ species have been observed around floating objects, see Castro et al. 2002), but also to investigate the underlying mechanisms responsible for patterns of residence times of any organism at a specific location.
Acknowledgements. The authors are deeply indebted to many colleagues who volunteered their time for scientific diving, fishing and tagging. Data collection was funded by Cooperative Agreement number NA17RS1230 between the Joint Institute for Marine and Atmospheric Research (JIMAR) and the National Oceanographic and Atmospheric Administration (NOAA). The views expressed herein are those of the authors and do not necessarily reflect the views of NOAA or any of its sub-agencies. The experiments comply with the current laws of the country in which the experiments were performed. Data analyses were carried out with financial support from the Commission of the European Communities, specific RTD programme of Framework Programme 7, 'Theme 2 - Food, Agriculture, Fisheries and Biotechnology', through the research project MADE (Mitigating adverse ecological impacts of open ocean fisheries). It does not necessarily reflect its views and in no way anticipates the Commission's future policy in this area.

\section{LITERATURE CITED}

Akaike H (1973) Information measures and model selection. Bull Int Stat Inst 50:277-290

Barraquand F, Benhamou S (2008) Animal movements in heterogeneous landscapes: identifying profitable places and homogeneous movement bouts. Ecology 89: 3336-3348

Brill RW, Block BA, Boggs CH, Bigelow KA, Freund EV, Marcinek DJ (1999) Horizontal movements and depth distribution of large adult yellowfin tuna (Thunnus albacares) near the Hawaiian Islands, recorded using ultrasonic telemetry: implications for the physiological ecology of pelagic fishes. Mar Biol 133:395-408

Capello M, Soria M, Cotel P, Deneubourg JL, Dagorn L (2011) Quantifying the interplay between environmental and social effects on aggregated-fish dynamics. PLoS ONE 6:e28109

Castro JJ, Santiago JA, Santana-Ortega AT (2002) A general theory on fish aggregation to floating objects: an alternative to the meeting point hypothesis. Rev Fish Biol Fish 11:255-277

Cayré P, Chabanne J (1986) Marquage acoustique et comportement de thons tropicaux (albacore: Thunnus albacares, et listao: Katsuwonus pelamis) au voisinage d'un dispositif concentrateur de poissons. Oceanogr Trop 21: 167-183

Cayré P, Marsac F (1993) Modelling the yellowfin tuna (Thunnus albacares) vertical distribution using sonic tagging results and local environmental parameters. Aquat Living Resour 6:1-14

Cox D (1972) Regression models and life tables (with discussion). J R Stat Soc Series B:187-220

Dagorn L, Freon P (1999) Tropical tuna associated with floating objects: a simulation study of the meeting point hypothesis. Can J Fish Aquat Sci 56:984-993

> Dagorn L, Bach P, Josse E (2000) Movement patterns of large bigeye tuna (Thunnus obesus) in the open ocean, determined using ultrasonic telemetry. Mar Biol 136: 361-371

Dagorn L, Holland KN, Itano DG (2007) Behavior of yellowfin (Thunnus albacares) and bigeye (T. obesus) tuna in a network of fish aggregating devices (FADs). Mar Biol 151:595-606 
Fonteneau A, Pallares P, Pianet R (2000) Worldwide review of purse-seine fisheries on FADs. In: Le Gall JY, Cayré P, Taquet $M$ (eds) Pêche thonière et dispositifs de concentration de poissons. Ifremer, Plouzané, p 15-35

Freon P, Dagorn L (2000) Review of fish associative behaviour: toward a generalisation of the meeting point hypothesis. Rev Fish Biol Fish 10:183-207

- Girard C, Benhamou S, Dagorn L (2004) FAD: Fish Aggregating Device or Fish Attracting Device? A new analysis of yellowfin tuna movements around floating objects. Anim Behav 67:319-326

Graham BS, Grubbs D, Holland K, Popp BN (2007) A rapid ontogenetic shift in the diet of juvenile yellowfin tuna from Hawaii. Mar Biol 150:647-658

Hall MA (1992) The association of tunas with floating objects and dolphins in the Eastern Pacific ocean. In: International workshop on the ecology and fisheries for tunas associated with floating objects, Book VII. Some hypotheses on the mechanisims governing the association of tunas with floating objects and dolphins. InterAmerican Tropical Tuna Commission, La Jolla, CA

$>$ Hallier JP, Gaertner D (2008) Drifting fish aggregation devices could act as an ecological trap for tropical tuna species. Mar Ecol Prog Ser 353:255-264

Heupel MR, Semmens JM, Hobday AJ (2006) Automated acoustic tracking of aquatic animals: scales, design and deployment of listening station arrays. Mar Freshw Res 57:1-13

Holland KN, Brill RW, Chang RKC (1990) Horizontal and vertical movements of yellowfin and bigeye tuna associated with Fish Aggregating Devices. Fish Bull 88: 493-507

Klimley AP, Holloway CF (1999) School fidelity and homing synchronicity of yellowfin tuna, Thunnus albacares. Mar Biol 133:307-317

Marsac F, Fonteneau A, Ménard F (2000) Drifting FADs used in tuna fisheries: an ecological trap? In: La Gall JY, Cayré

Editorial responsibility: Konstantinos Stergiou,

Thessaloniki, Greece
$\mathrm{P}$, Taquet $\mathrm{M}$ (eds) Pêche thonière et dispositifs de concentration de poissons. Ifremer, Plouzané, p 537-552

- Menard F, Stequert B, Rubin A, Herrera M, Marchal E (2000) Food consumption of tuna in the Equatorial Atlantic ocean: FAD-associated versus unassociated schools. Aquat Living Resour 13:233-240

> Musyl MK, Brill RW, Boggs CH, Curran DS, Kazama TK, Seki MP (2003) Vertical movements of bigeye tuna (Thunnus obesus) associated with islands, buoys, and seamounts near the main Hawaiian Islands from archival tagging data. Fish Oceanogr 12:152-169

Ohta I, Kakuma S (2005) Periodic behavior and residence time of yellowfin and bigeye tuna associated with fish aggregating devices around Okinawa Islands, as identified with automated listening stations. Mar Biol 146: 581-594

Schaefer KM, Fuller DW (2002) Movements, behavior, and habitat selection of bigeye tuna (Thunnus obesus) in the eastern equatorial Pacific, ascertained through archival tags. Fish Bull 100:765-788

Schaefer KM, Fuller DW (2010) Vertical movements, behavior, and habitat of bigeye tuna (Thunnus obesus) in the equatorial eastern Pacific Ocean, ascertained from archival tag data. Mar Biol 157:2625-2642

Schaefer KM, Fuller DW, Block BA (2007) Movements, behavior, and habitat utilization of yellowfin tuna (Thunnus albacares) in the northeastern Pacific Ocean, ascertained through archival tag data. Mar Biol 152: 503-525

Soria M, Dagorn L, Potin G, Freon P (2009) First field-based experiment supporting the meeting point hypothesis for schooling in pelagic fish. Anim Behav 78:1441-1446

Voegeli FA, Pincock DG (1996) Overview underwater acoustics as it applies to telemetry. In: Baras E, Philippart JC (eds) Proc Underwater Biotelemetry, Proc 1st Conf and Workshop on Fish Telemetry in Europe. University of Liège, Liège, p 235-241

Submitted: March 30, 2012; Accepted: February 8, 2013 Proofs received from author(s): May 25, 2013 